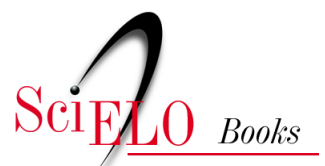

\title{
eduepb
}

\section{O Cinema como Artefato Semiótico Mediador da Compreensão e Potencialização dos Processos de Ensino-Aprendizagem}

\author{
Fábio Marques de Souza
}

\section{SciELO Books / SciELO Livros / SciELO Libros}

SOUZA, F. M. O Cinema como Artefato Semiótico Mediador da Compreensão e Potencialização dos Processos de Ensino-Aprendizagem. In: ARANHA, S. D. G., and SOUZA, F. M., eds. Práticas de ensino e tecnologias digitais [online]. Campina Grande: EDUEPB, 2018, pp. 143-180. Ensino e aprendizagem collection, vol. 3. ISBN: 978-85-78795-26-9. http://doi.org/10.7476/9786586221657.0007.

\section{(c) (i)}

All the contents of this work, except where otherwise noted, is licensed under a Creative Commons Attribution 4.0 International license.

Todo o conteúdo deste trabalho, exceto quando houver ressalva, é publicado sob a licença Creative Commons Atribição 4.0.

Todo el contenido de esta obra, excepto donde se indique lo contrario, está bajo licencia de la licencia Creative Commons Reconocimento 4.0. 


\title{
O CINEMA COMO ARTEFATO SEMIÓTICO MEDIADOR DA COMPREENSÃO E POTENCIALIZAÇÃO DOS PROCESSOS DE ENSINO-APRENDIZAGEM
}

\author{
Fábio Marques de Souza ${ }^{1}$
}

1 Docente permanente e Coordenador Adjunto do PPGFP/UEPB (Mestrado Profissional em Formação de Professores). Atualmente, está credenciado, como professor colaborador no POSLE/UFCG (Mestrado Acadêmico em Linguagem e Ensino) e no PPGEduC/ UFPE (Mestrado Acadêmico em Educação Contemporânea). Professor efetivo do Departamento de Letras e Artes da UEPB/ Campus I. Editor da coleção Ensino \& Aprendizagem, da EdUEPB. Cursou estágio de pós-doutorado no Programa de Pós-graduação em Educação Contemporânea (PPGEduC/UFPE), com pesquisa acerca da mediação, com o apoio das Tecnologias Digitais da Informação e Comunicação. Mestre e Doutor em Educação, tendo como foco de investigação o ensino-aprendizagem de Língua Estrangeira/Adicional e a formação de professores de línguas, obtidos, respectivamente, pela UNESP/Marília (2009) e pela Faculdade de Educação da USP (2014). Licenciado em Letras (UNESP/Assis - 2006) e em Pedagogia (UNINOVE - 2014). Líder dos grupos de pesquisa TECLIN, Tecnologias, Culturas e Linguagens e Formação de Professores de Línguas Estrangeiras/Adicionais da UEPB e membro do grupo de pesquisa Estudos Bakhtinianos (UNESP/CNPq). Tem experiência na educação básica e no ensino superior (no âmbito público e privado) e na autoria de materiais didáticos de Português, Inglês e Espanhol como línguas adicionais. email - fabiohispanista@gmail.com 


\section{Introdução}

As reflexões apresentadas neste artigo são mediadas pelo cinema, considerado - conforme a perspectiva sociocultural - como artefato cultural, ferramenta de mediação simbólica potencializadora do desenvolvimento humano. Ao adotarmos termos como artefato e ferramenta, não pretendemos reduzir a arte a um mero caráter utilitário. Pelo contrário, segundo a perspectiva sociocultural que comungamos, estes termos ganham uma dimensão ampla já que a relação homem-mundo é uma relação mediada por artefatos e ferramentas físicas, sociais e simbólicas, como explicaremos a seguir.

Neste sentido, para Vigotski, a relação do homem com o mundo não é uma relação direta, mas, fundamentalmente, mediada por sistemas simbólicos. Complementando, Vieira Abrahão (2012) nos apresenta a mediação como um conceito central da teoria sociocultural, "sendo o processo por meio do qual os seres humanos se utilizam de artefatos culturalmente construídos, de conceitos e de atividades para regular o mundo material ou seu próprio mundo e suas atividades sociais e mentais reciprocamente" (p. 5).

Dessa forma, a mediação pode se dar por instrumentos ou signos:

O signo age como um instrumento da atividade psicológica de maneira análoga ao papel de um instrumento no trabalho. Os instrumentos, porém, são elementos externos ao indivíduo, voltados para fora dele; sua função é provocar mudanças nos objetos, controlar processos da natureza. Os 
signos, por sua vez, também chamados por Vygotsky de 'instrumentos psicológicos' são orientados para o próprio sujeito, para dentro do indivíduo; dirigem-se ao controle de ações psicológicas, seja do próprio indivíduo, seja de outras pessoas. São ferramentas que auxiliam nos processos psicológicos e não nas ações concretas, como os instrumentos (OLIVEIRA, 1993, p. 30).

Em consonância com esta reflexão, Johnson (2009) acrescenta que as ferramentas das quais lançamos mão para a mediação da nossa relação com o mundo podem ser físicas, sociais ou simbólicas. Diante do exposto, neste capítulo, partindo do pressuposto de que nossas reflexões acerca das crenças que permeiam a aquisição da língua espanhola e o tratamento da variação linguística por professores brasileiros deste idioma em formação inicial serão mediadas pelo cinema, apresentaremos o potencial da sétima arte em levar à tela de projeção a vida em seus múltiplos aspectos, enfatizando o potencial representacional das inquietações e desejos mais íntimos da alma humana.

Teceremos considerações a respeito das várias vias de estudo com vistas à compreensão do cinema, com foco na indústria, nas artes, nas invenções, no entretenimento e ressaltamos seu potencial para propiciar a compreensão da cultura escolar, bem como sua capacidade de potencializar o processo de ensino-aprendizagem.

Neste texto empregamos o termo cinema em sentido amplo, como imagem em movimento, independente do 
suporte, exceto quando fizermos referência explícita nesse sentido.

A primeira sessão. 28 de dezembro de 1895. No salão indiano do Grand Café, bulevar dos Cupuchinhos, em Paris, os trinta e três convidados dos irmãos Lumière vão assistir a um extraordinário espetáculo. Sobre uma pequena tela, uma fotografia recém-projetada de repente ganha vida. Carros, cavalos, pedestres começam a andar. Toda a vida de uma rua aparece. 'Diante desse espetáculo, ficamos boquiabertos', declarará o célebre prestigiador Georges Méliès. A invenção em breve vai atrair multidões e dar volta ao mundo (MARCHAND, 1995, p.6).

É consenso entre os estudiosos que a definição inicial para o cinema foi uma técnica de registro do movimento. Entretanto, ao longo da história, com acréscimos de elementos estéticos, sons, mudança de planos, angulações, enquadramentos, movimentos de câmera, iluminações e tecnologia, passou a ser reconhecido como "a sétima arte" e se apresenta como uma das mais ricas e completas manifestações artísticas que o ser humano já teve a capacidade de desenvolver; isto porque o fazer cinematográfico engloba todos os demais processos de criação artística já vividos (música, dança, pintura, escultura, teatro e literatura). 
Além de representar a vida, a arte cinematográfica dá forma às inquietações e desejos mais íntimos da alma humana. O filme reúne extraordinário número de informações nas diferentes áreas da experiência. As discussões sobre o cinema - ao longo do tempo - têm se encaminhando por diversos focos: o da indústria, das artes, das invenções, do entretenimento.

Silva (2006), ao tecer reflexões acerca do cinema e os vínculos sociais, utiliza a cena do filme Ônibus $174 \mathrm{em}$ que aparece o ônibus com o sequestrador, de arma na mão, com um apanhado de corpos confinados pelo terror num veículo estático, como uma metáfora da vida contemporânea. Para ela, apesar da "violência do filme, um ônibus parado e um entorno de imagens em movimento são metáforas da vida urbana, território atual do sedentarismo de seres que eram, na sua sociabilidade inicial, nômades (p.227)".

De acordo com a autora, o cinema realiza, para o homem sedentário, a viagem que o espírito anseia, sem que haja a necessidade de deslocamento de lugar. Apesar de o movimento relacionar-se ao prazer, no cinema há a dualidade entre esse e a angústia devido ao fato de ser o movimento nada mais do que um contínuo de imagens luminosas em fotogramas sucessivos que são ampliados de forma simbólica pela montagem. É ele o responsável por transformar as lacunas entre os fotogramas, intermediando a ligação com o sentido do movimento. "A imagem-movimento do cinema é, assim, um 'entre', um ponto médio entre duas imagens, como pretende Deleuze, uma ausência-presença que simboliza a perfeição, o conflito prazer angústia produzida pelo cinema" (p. 228). 
O cinema, além de mascarar a saciedade de carência de movimento deste homem que um dia foi nômade, cumpre a função da fabulação necessária ao espírito, conforme nos apresenta Cândido (1995). A partir das afirmações deste autor, podemos apreciar a arte como uma necessidade básica, já que se trata da manifestação universal de todos os homens em todos os tempos:

Não há povo e não há homem que possa viver sem ela, isto é, sem a possibilidade de entrar em contato com alguma espécie de fabulação. Assim como todos sonham todas as noites, ninguém é capaz de passar as vinte e quatro horas do dia sem alguns momentos de entrega ao universo fabulado. $\mathrm{O}$ sonho assegura durante o sono a presença indispensável deste universo, independente da nossa vontade. E durante a vigília a criação ficcional (...) está presente em cada um de nós, analfabeto ou erudito, como anedota, causo, história em quadrinho, noticiário policial, canção popular, moda de viola, samba carnavalesco. Ela se manifesta desde o devaneio amoroso ou econômico no ônibus até a atenção fixada na novela de televisão ou na leitura de um romance (p. 242).

Ao argumentar sobre o direito à literatura, que - neste contexto - expandimos às artes, grupo no qual o cinema se encaixa, sabemos que as manifestações artísticas 
correspondem "a uma necessidade universal que deve ser satisfeita sob pena de mutilar a personalidade, porque pelo fato de dar forma aos sentimentos e à visão do mundo ela nos organiza, nos liberta do caos e, portanto, nos humaniza" (CÂNDIDO, 1995, p. 256).

Humanização aqui é entendida como um processo que caracteriza o homem com traços ditos essenciais: capacidade de refletir, de adquirir conhecimento e sabedoria, boa disposição ao relacionar-se com o outro, afinamento das emoções e capacidade de percepção do que é belo e complexo.

\section{O cinema nos permite outras maneiras de olhar para 0 mundo e, assim, compreender a nós mesmos}

Adentramos a sala de projeção e somos envolvidos num emaranhado de imagens e sons que atinge nossa alma, expondo nossas paixões, frustrações, desejos, inquietações. Uma breve análise pela trajetória do cinema nos revelará que, desde a década de 1960, a sétima arte vem passando por uma mudança de abordagem e tem se transformado em um dos mais fortes canais de comunicação e significação sociocultural. Neste sentido, Turner (1997), ao nos apresentar o cinema como prática social, nos alerta para o fato de que compreender um filme não é essencialmente uma prática estética; é uma prática social que mobiliza toda uma gama de sistemas no âmbito da cultura.

Ao pensarmos no cinema a partir do tema arte e entretenimento na contemporaneidade, devemos levar em consideração que ele vai além da projeção do filme e constitui um complexo sistema constituído por elementos como a 
indústria, o mercado de filmes, o roteiro, o argumento, as locações, os atores, a produção, as interpretações, as conversas depois do filme, dentre tantas outras coisas.

Almeida (1994) cita a sala de projeção como o local de encontro entre os que produzem e os que o consomem o cinema. Para ele, trata-se do momento estético em que um objeto artística e tecnicamente produzido vai ao encontro do imaginário do espectador, relaciona-se intimamente com seus desejos, ressentimentos, vontades, ilusões, raivas, prazeres, traumas, vivências, e sobre o qual só teremos nossa objetividade restituída após o término da projeção.

Com o seu aparato tecnológico apropriado para documentar, registrar de forma estética e narrar histórias, o cinema nos permite uma nova maneira de olhar para o mundo e, com isso, estabelece uma forma peculiar de inteligibilidade e conhecimento. Esta arte pode ser utilizada, desde a educação infantil ao ensino superior, como um dispositivo didático lúdico e atrativo, valioso na formação de novas gerações, possibilitando o encontro simultâneo com a cultura cotidiana e erudita, pois é o campo no qual a estética, o entretenimento, a ideologia e os valores sociais mais amplos são sintetizados numa mesma obra.

Quanto mais o espectador de cinema se empenhar em compreender/analisar os filmes aos quais assiste, maiores serão as chances de se aproximar da intencionalidade e seleção de sentidos pretendidas pelos idealizadores, das características culturais e das ideologias de suas escolhas, permitindo compará-las a sua própria cultura e valores. Neste sentido, do relacionamento espectador-filme pode surgir uma consciência humano-social com capacidade de resignificar o audiovisual e ir além dele, num processo 
quase subliminar, propício à formação de novas percepções e entendimento da vida em sociedade.

Neste sentido, Trevizan (1998) aponta que o potencial artístico de um bom filme não se sustenta somente no reconhecimento da credibilidade da história contada, mas reside, sobretudo, na possibilidade de a linguagem criada estabelecer com o espectador um nível profundo de comunicação intelectual, filosófica, psicológica, emocional, fazendo com que ele reflita sobre si mesmo e sobre o outro.

Diante do exposto, nosso objetivo neste artigo é, a partir da pesquisa bibliográfica, apresentar as contribuições do cinema para a compreensão e potencialização do processo de ensino-aprendizagem. Neste intuito, iniciamos nosso trajeto refletindo acerca da sociedade contemporânea, submersa em imagens, sons e movimentos. Na sequência, apresentamos a capacidade do cinema em nos permitir outras maneiras de olhar para o mundo e, assim, compreender a nós mesmos. No próximo item, nos dedicaremos aos vários usos do cinema e vídeo na escola, a possibilidade da pesquisa em educação com base nas artes, algumas contribuições da prática cineclubista e as contribuições do cinema no aprimoramento da competência intertextual.

\section{A sociedade submersa em imagens, sons e movimentos}

É inegável a presença das imagens, sons e movimentos em nosso cotidiano. Já é consenso entre vários estudiosos que o cinema não nasceu mudo, mas em meio a narradores, explicadores, conferencistas, conversas, cantorias, 
enfim, em uma grande intersemiose. Neste ponto, damos destaque à compreensão da importância do montador na construção dos sentidos em meio ao emaranhado de signos que compõem uma cena. O próprio cinema nos tornou mais conscientes disto, por exemplo, quando nos apresentou Elizaveta Svilova restaurando o tempo em O homem com a Câmera (VERTOV, 1929). Atualmente, a produção e a circulação de imagens se dão de forma interativa e dinâmica, como aponta Di Camargo (2009):

Desde as tradicionais artes plásticas, passando pela fotografia, pelo cinema, pela TV e chegando à Internet, o homem tem utilizado diversos recursos para se comunicar através da imagem. E, analisando os contextos da produção imagética, percebe-se que as imagens estão ligadas à arte, ao jornalismo, à publicidade, enfim, aos vários campos de produção de sentido, como um elemento imprescindível para o processo de comunicação (p. 27-28).

As linguagens audiovisuais têm presença marcante na produção cultural contemporânea, o que pode ser observado desde a propaganda até a sofisticada produção cinematográfica contemporânea. São vários os gêneros que utilizam a linguagem audiovisual como ferramenta essencial: filmes, telenovelas, vídeos, minisséries e videoclipes, os quais estão cada vez mais presentes em nossa cultura e tecnologicamente mais sofisticados. 
É inegável a revolução causada pela Internet na produção e circulação da linguagem audiovisual. A teia de alcance mundial mudou nossa forma de acesso à informação; a maneira de concebê-la (de forma hipertextual e multimodal); nossa forma de entretenimento e o panorama educacional. Cabe destacar também que a internet possibilita ao usuário a possibilidade de desempenhar um papel ativo, de emissor criador de conteúdo audiovisual e não somente o tradicional consumidor de conteúdo. Diante da gama de possibilidades para criação e consumo de produtos audiovisuais, faz-se necessário sensibilizar o espectador para compreender os vários discursos presentes nos produtos culturais transmitidos pela mídia:

Principalmente [pela] televisão, objeto popular de consumo, canal ideal para a propagação da cultura de massa. E também o cinema, uma forma complexa de fazer arte que difere das tradicionais em diversos aspectos. Sem a intenção de fazer um julgamento preconceituoso, faz-se necessário realizar uma leitura mais crítica dessa linguagem cada vez mais sofisticada. E conveniente rever o modo como enxergamos a comunicação de massa, a fim de que possamos participar, de forma politizada, desse processo de produção e consumo (DI CAMARGO, 2009, p. 28). 
O audiovisual é a linguagem do principal meio2 de comunicação social e tem presença marcante na produção cultural contemporânea, o que pode ser observado desde a propaganda até a sofisticada produção cinematográfica contemporânea. São vários os gêneros que utilizam a linguagem audiovisual como ferramenta essencial: filmes, telenovelas, vídeos, minisséries e videoclipes, os quais estão cada vez mais presentes em nossa cultura e tecnologicamente mais sofisticados (DI CAMARGO, 2009).

Vários estudiosos destacam as potencialidades da sétima arte no processo educativo. Napolitano (2003, p. 11-12), por exemplo, comenta que o trabalho com o cinema pode auxiliar a escola a reencontrar a cultura ao mesmo tempo cotidiana e elevada, pois o cinema é o campo no qual a estética, o lazer, a ideologia e os valores sociais mais amplos são sintetizados numa mesma obra de arte.

Neste sentido, Trevizan (1998, p. 85) cita que o filme congrega informações nas diferentes áreas da experiência humana e por isso deve ser utilizado, nas escolas, com o um instrumento didático. A autora destaca ainda o papel valioso desta mídia na formação de novas gerações.

\section{Os vários usos do cinema e vídeo na escola}

Em artigo acerca do vídeo na sala de aula, Moran (1995, p. 27) destaca que este dispositivo auxilia o bom professor, atrai os alunos, mas não modifica substancialmente a relação pedagógica. $\mathrm{O}$ pesquisador argumenta que as mídias aproximam a sala de aula do cotidiano, das

2 Do latim medius, com plural em media, que nos remete à mídia. 
linguagens de aprendizagem e comunicação da sociedade urbana, mas também introduz novas questões no processo educacional.

$\mathrm{O}$ autor nos apresenta vários usos do vídeo em sala de aula. Como usos inadequados, temos o vídeo-tapa-buraco; vídeo-enrolação; vídeo-deslumbramento e o vídeo-perfeição. Como possibilidades desejáveis de utilização o pesquisador relaciona o vídeo como sensibilização, ilustração, simulação, conteúdo de ensino, produção, avaliação, espelho e interação/suporte de outras mídias. Comentaremos, a seguir, cada uma dessas categorias elencadas.

Para ele, o "vídeo-tapa-buraco" ocorre quando exibimos um vídeo para sanar um problema inesperado, como, por exemplo, a falta do professor. O autor argumenta que "usar este expediente eventualmente pode ser útil, mas se for feito com frequência desvaloriza o uso do vídeo e o associa - na cabeça do aluno - a não ter aula" (MORAN, 2003, p. 34).

O "vídeo-enrolação" aconteceria com a exibição de um vídeo sem muita relação com o conteúdo que está sendo estudado. Nesta situação, o alunado até pode não reclamar na hora e ser coautor do mau uso, mas sabe que o vídeo é usado como forma de camuflar a aula.

Outra situação seria o "vídeo-deslumbramento", que ocorre quando o professor que acaba de descobrir o uso do vídeo se empolga e passa vídeo em todas as aulas, esquecendo outras dinâmicas mais pertinentes, neste caso, "o uso exagerado do vídeo diminui a sua eficácia e empobrece as aulas" (MORAN, 2003, p. 34).

Situações negativas causadas pelo professor que sempre questiona todos os vídeos possíveis, apresentado 
defeitos de informação ou estéticos, são consideradas pelo autor de "vídeo perfeição". Segundo ele, as obras sempre serão representações e, no caso dos "vídeos que apresentam conceitos problemáticos podem ser usados para descobri-los, junto com os alunos, e questioná-los" (MORAN, 2003, p. 34).

Outra forma indesejada de utilização consiste no "só vídeo", quando o professor não explora o material, ficando na mera exibição, sem discussão e nem integração com outros assuntos da aula.

Dentre as propostas desejáveis de utilização, o autor apresenta o "vídeo como sensibilização", como um dos mais importantes na escola: "um bom vídeo é interessantíssimo para introduzir um novo assunto, para despertar a curiosidade, a motivação para novos temas. Isso facilitará o desejo de pesquisa nos alunos para aprofundar o assunto do vídeo e da matéria" (MORAN, 2003, p. 34).

O "vídeo como ilustração" tem o potencial de reunir muitos contextos, na maioria das vezes distantes da realidade do aluno, em uma só mídia e permite exemplificar e/ou complementar o que é visto em sala de aula, auxiliando os alunos na compreensão de cenários desconhecidos, de outros tempos históricos. Neste sentido, "a vida se aproxima da escola através do vídeo" (MORAN, 2003, p. 35). O pesquisador argumenta que um vídeo pode trazer para a sala de aula realidades distantes dos alunos, como, por exemplo, a Amazônia ou a África.

O cinema pode ser utilizado em atividades que visem desmistificar conceitos cristalizados acerca da língua e cultura estrangeira que está sendo estudada, como no caso do espanhol, pois permite apresentar diversas realidades e variedades linguísticas e culturais num mesmo 
contexto, isto é, na sala de aula, de maneira a permitir o trabalho com as crenças e a desconstrução de estereótipos negativos.

Neste sentido, o cinema pode ser um material didático, definido pelas Orientações Curriculares para o Ensino Médio - Espanhol, como o conjunto de recursos dos quais os professores se valem em suas práticas pedagógicas, "entre os quais se destacam, grosso modo, os livros didáticos, os textos, os vídeos, as gravações sonoras (de textos, canções), os materiais auxiliares ou de apoio, como gramáticas, dicionários, entre outros" (OCEM, 2008, p. 154) que exercem um papel importante na sala de aula.

A utilização do cinema como recurso didático pode propiciar momentos de encontro com o Outro, sua língua e sua cultura, e mostrar aos alunos realidades muitas vezes desconhecidas e distantes, tornando o aprendizado mais significativo e prazeroso.

Neste sentido, já é sabido que para que o ensino de uma língua seja mais eficaz é necessário não só aprender gramática, mas ir além da simples sensibilização do aluno quanto a questões socioculturais, como afirma Goettenauer (2005):

A questão não é apenas sensibilizar o aluno e buscar formas para ensejar atitudes imparciais diante de outros valores, outras tradições, outros modos de ver, viver, e nomear a realidade. Trata-se de algo bem mais complexo: acolher o outro e compartilhar com ele hábitos, costumes, ideias (...). Apropriar-se de uma 
língua distinta da materna é apropriar-se de novas lentes para mirar o mundo (p. 64).

Outra rica possibilidade é o "vídeo como simulação" já que nos permite ilustrar a aula de forma mais sofisticada, por exemplo, "o vídeo pode simular experiências de química que seriam perigosas em laboratório ou que exigiriam muito tempo e muitos recursos. Um vídeo pode mostrar o crescimento acelerado de uma planta, de uma árvore - da semente até a maturidade - em poucos segundos" (MORAN, 2003, p. 35).

O "vídeo como conteúdo de ensino", parte do pressuposto de que a mídia pode abordar temas direta ou indiretamente. Ao apresentar o "vídeo como produção", o autor subdivide esta categoria em três itens: a) como documentação, registro de eventos, aulas, estudos do meio, experiências, entrevistas, depoimentos; b) Como intervenção: interferir, modificar um determinado programa, um material audiovisual, acrescentando uma trilha sonora ou editando o material de forma compacta ou introduzindo novas cenas com novos significados, "assim como ele interfere num texto escrito, modificando-o, acrescentando novos dados, novas interpretações, contextos mais próximos do aluno" (MORAN, 2003, p. 35); c) como expressão, como nova forma de comunicação, adaptada à sensibilidade principalmente das crianças e dos jovens:

As crianças adoram fazer vídeo e a escola precisa incentivar ao máximo a produção de pesquisas em vídeo pelos alunos. A produção em vídeo 
tem uma dimensão moderna, lúdica. Moderna como um meio contemporâneo, nova e que integra linguagens. Lúdica, pela miniaturização da câmera, que permite brincar com a realidade, levá-la junto para qualquer lugar. Filmar é uma das experiências mais envolventes tanto para as crianças como para os adultos. Os alunos podem ser incentivados a produzir dentro de uma determinada matéria, ou dentro de um trabalho interdisciplinar. E também produzir programas informativos, feitos por eles mesmos e colocá-los em lugares visíveis dentro da escola e em horários em que muitas crianças possam assistir a eles (MORAN, 2003, p. 36).

Outra proposta seria a do "vídeo como avaliação", o que inclui os alunos, o professor, e o processo de ensino-aprendizagem. $\mathrm{O}$ autor destaca também o "vídeo-espelho"; nele, "vejo-me na tela para poder compreender-me, para descobrir meu corpo, meus gestos, meus cacoetes" (MORAN, 2003, p. 36). Esta categoria permite a análise do grupo e dos papéis de cada um, para acompanhar o comportamento individual, do ponto de vista participativo, para incentivar os mais retraídos e pedir aos que falam muito para darem mais espaço aos colegas. $\mathrm{O}$ autor argumenta também que o vídeo-espelho é de grande utilidade para o professor se ver, examinar sua comunicação com os alunos, suas qualidades e defeitos.

A última possibilidade apresentada seria a do "vídeo como interação/suporte de outras mídias"; nela o autor 
destaca o vídeo como suporte da televisão e do cinema e a interação do vídeo com outras mídias, como o computador, celular, videogames, internet.

\section{Pesquisa em educação com base nas artes}

Neste momento, compartilharemos das ideias de Moraes (2004, p. 53), para quem os filmes, além de um recurso para a prática educacional - na medida em que os utilizamos em sala de aula -, podem ser objetos de pesquisa - nos quais buscamos entender as várias lentes que se cruzam na representação da cultura escolar.

Dessa forma, é possível ir além da exploração da sétima arte como recurso para a prática educacional, partindo para o texto fílmico como objeto de pesquisa para a compreensão das funções, objetivos, práticas e agentes escolares veiculados por esta mídia.

Levando-se em consideração que a linguagem cinematográfica estabelece com o espectador uma comunicação intelectual, filosófica, psicológica e emocional, fazendo com que ele reflita sobre si mesmo e sobre o outro, é possível analisar os diversos recursos da linguagem cinematográfica utilizados pelos cineastas e como essas opções estéticas influenciam na construção do olhar do espectador sobre a realidade escolar, bem como a escola é representada pela sétima arte. Isto é, como as produções cinematográficas colaboram na construção de referência do imaginário a respeito do ambiente escolar. 
Propostas neste sentido se inserem no campo da Pesquisa Educacional com base nas Artes ${ }^{3}$, via pesquisa qualitativa de cunho interpretativista que, concebendo o cinema como prática social e a partir da teoria da representação cultural, pretende compreender as vozes engendradas pela linguagem cinematográfica para compor as narrativas fílmicas nas quais é retratada a cultura escolar.

Embora o trabalho dos artistas seja sempre considerado da perspectiva ampla da criatividade, vários artistas contemporâneos se empenham na realização de formas altamente sistemáticas e profundas de pesquisa... Ao prepararem um espetáculo teatral, por exemplo, diretores, dramaturgos e atores frequentemente realizam uma ampla investigação da linguagem e dos costumes daquele período ou mesmo a história das produções daquele determinado trabalho (...). Compositores e artistas performáticos pesquisam, coletam histórias orais e se empenham em estudos etnográficos sem dar nomes ao que fazem (SABATINI, 1993 apud TELLES, 2004).

Telles (2006) relata que um dos pioneiros a citar o potencial das artes para buscar instrumentos e formas alternativas de representação das pesquisas em educação

3 Arts-Based Educational Research (EISNER, 1991, 1997; DIAMOND \& MULLEN, 1999; TELLES, 2004 e 2005), Arts-informed Research ou Arts-Based Approaches to Qualitative Inquiry (GRAY, 2003). 
foi Eisner (1991). Para esse educador, as artes têm uma longa tradição em descrever, interpretar e avaliar o mundo e dar forma à experiência.

Exemplos de experiências vicárias são encontrados nas artes. Por meio da forma artística de pesquisa conhecida como narrativas de histórias educacionais, o leitor pode experienciar, de forma vicária, um mundo virtual crível da escola ou sala de aula, habitado por pessoas que são as personagens virtuais da história. Este tipo de experiência estética pode ser suficientemente significativa a ponto de causar um questionamento das premissas fundamentais dos valores, assim como das bases ideológicas sobre as quais as decisões relativas à educação são tomadas. (DENZIN, 1992, p. 15).

Nesta perspectiva do cinema como fonte de pesquisa para a compreensão das possíveis representações da cultura escolar, cabe citar Pinheiro (2010), Fabris (2005) e as pesquisas de Telles $(2004,2005)$.

A dissertação de mestrado de Pinheiro (2010) verifica as representações sociais relacionadas à escola a partir da comparação das imagens levadas à tela pela produção francesa Os incompreendidos (1959) e pelo filme chileno Machuca (2004).

Outro trabalho nesta linha com o qual tivemos contato é a tese de Fabris (2005). Nela, a autora toma o cinema como objeto de compreensão da cultura escolar e analisa 
como o cinema brasileiro representa a escola e o trabalho docente no contexto de dezessete filmes nacionais.

Telles (2004) utiliza o espetáculo teatral como dispositivo de reflexão e representação do desenvolvimento do professor e tece reflexões acerca da pesquisa educacional com base nas artes e na reflexão compartilhada, defendendo a necessidade de formas alternativas de representação da docência e do conhecimento dos professores.

\section{Contribuições da prática cineclubista para a formação humana}

Conforme cita Andrade (2010, p. 212), “o [sistema] cineclubista é aquele que se dedica a divulgar e discutir o cinema como obra de arte, como pensamento, como renovação do olhar, do pensar e do sentir. E não como consumo, pura e simplesmente". Macedo (2005, p. 29) apresenta-nos três características dos cineclubes: i) não ter fins lucrativos; ii) possuir uma estrutura democrática; iii) ter um compromisso cultural e ético.

Segundo o autor, os primeiros cineclubes apareceram como uma resposta quase que automática ao excesso de estandardização que o monopólio do cinema ia instaurando. Os coletivos se agruparam cheios de ilusões sobre a "sétima arte" e o papel do "belo". No entanto, mesmo assim, eles já surgiram como uma organização sem fins lucrativos - o que os diferenciava dos valores de mercado -, já nasceram baseados numa estrutura coletiva e democrática (em maior ou menor grau, mas sempre democrática) e se formaram com uma comprovada disposição de se contrapor ao poder monopolizado e alienador do cinema comercial, ressaltando as produções que não encontravam 
distribuição no mercado comercial ou que eram repelidas por motivos estéticos, políticos. Dessa forma, os cineclubes afloraram como uma maneira de organização coletiva.

Além de permitir ao homem sedentário, que incialmente era nômade, a viagem da alma sem que o corpo saia do lugar o cinema também teve, em seu início um caráter de nomadismo que ainda hoje permanece em algumas regiões do Brasil. Neste sentido, podemos destacar que as primeiras sessões de cinema realizadas no Brasil cumpriam essa função de movimentação simbólica, além de terem um caráter itinerante pela própria limitação técnica.

Atualmente, ocorre no Brasil um grande número de sessões semelhantes a essas primeiras por seu caráter nômade, itinerante, e arcaicamente comunitário. Elas reúnem espectadores em centros comunitários, quadras de esporte, ruas de bairros periféricos, hospitais, presídios, praças interioranas. A falta de salas específicas e adequadas para a exibição cinematográfica colabora em muito para que essa situação se dê. Segundo a Pesquisa de Informações Básicas Municipais do IBGE - Instituto Brasileiro de Geografia e Estatística, 92 por cento das cidades brasileiras não possuíam salas de cinema até 1999 (SILVA, 2006, p. 228).

A pesquisadora relata que as sessões comunitárias existentes até hoje não se dão unicamente pela falta de salas de projeção, mas pela necessidade de socialização 
do ser humano, já que "ver produtos da indústria cultural numa tela de cinema é participar afetivamente de um movimento lúdico que remete constantemente ao outro e, reflexivamente, a si mesmo (SILVA, 2006, p.229)".

A familiaridade e a vinculação institucional com o local de projeção conferem ao espaço da sessão comunitária uma significação diferente daquela atribuída à sala de cinema comercial. A movimentação das pessoas se dá de maneira mais fluida, aparentemente mais descontraída e festiva. O conhecimento dos espectadores entre si e com os organizadores do evento também modifica a qualidade da interação. Os indivíduos são reconhecidos como tal e isso diminui a formalidade dos procedimentos de aproximação, facilitando o encontro. Outros comportamentos típicos do anonimato (pôr os pês sobre o espaldar da cadeira da frente ou jogar lixo no chão) são inibidos. Ainda que seja assim, qualquer tipo de filme ou de sessão de cinema alimenta produções simbólicas e relações sociais que se estabelecem em torno do filme. Quando essas relações envolvem vínculos comunitários mais caracterizados, a mobilização do público é muito intensa, excede o evento (SILVA, 2006, p.229). 
Alves (2010) apresenta-nos a formação humana como um problema crucial do nosso tempo histórico; para ele "uma democracia sem democratização radical é o anseio oculto do capitalismo histórico" (p. 13). Neste sentido, o autor apresenta como característica a constituição do capitalismo manipulatório, "que se tornou hoje um sistema mundial organizado pela oligarquia industrial-financeira, que controla os aparatos de 'formação de opinião pública', sob o controle do capital concentrado dos grandes grupos da indústria cultural" (p. 13).

Diante da formação humana como um problema crucial do nosso tempo histórico, acreditamos que a prática cineclubista, principalmente em ambientes educacionais, pode colaborar para a promoção de uma formação integral e plena, já que, infelizmente, $90 \%$ das cidades brasileiras não têm sala de cinema, torna-se fundamental promover novas formas de acesso e difusão cultural:

No Brasil, para ficarmos exclusivamente no campo do audiovisual, apenas cerca de $10 \%$ dos municípios tem salas de cinema, e é esse também o percentual de brasileiros que vê algum filme no cinema pelo menos uma vez por ano. Se todos têm televisores, o acesso a programações diferenciadas (TV por assinatura), é da mesma magnitude que o cinema. $\mathrm{O}$ acesso regular à internet tem crescido muito, mas ainda é privilégio de uma minoria. A quase totalidade das comunidades brasileiras não tem museus, teatros, bibliotecas, etc. No 
resto da América Latina, África e grande parte da Ásia - onde se concentram $80 \%$ da população mundialos indicadores são semelhantes, frequentemente piores (MACEDO, 2010, p. 33).

Dito de outra maneira, o autor destaca que mais de 90\% dos municípios brasileiros não têm cinema e o mesmo percentual de exclusão se aplica ao público, já que menos de $10 \%$ da população do Brasil vai ao cinema pelo menos uma vez por ano. Macedo (2005) argumenta que o cinema ao qual um décimo da população brasileira tem acesso é o cinema "produzido no famoso distrito da cidade de Los Angeles, Hollywood, onde se concentra a indústria que controla $85 \%$ dos mercados cinematográficos de todo o mundo" (p. 4):

Esse 'produto' ocupa, de forma predatória, todo o espaço cultural, procurando substituir o imaginário do nosso povo, sufocado qualquer outra expressão e matando toda diversidade. Pois dentre esses $10 \%$ da população que vão [sic] ao cinema, são cerca de $10 \%$ os que veem um filme brasileiro ou de outra nacionalidade, inclusive os filmes americanos não produzidos pelas grandes corporações hollywoodianas. Em outras palavras, só $1 \%$ dos brasileiros têm algum contato com filmes brasileiros e de todo o resto do mundo, somados (MACEDO, 2005, p.5). 
Ao argumentar acerca da potencialidade dos cineclubes em espaços escolares, Alves (2010, p. 13) ressalta que, na medida em que a prática cineclubista conseguir elaborar metodologias pedagógicas capazes de irem além da mera exibição do filme e, inclusive, de mera discussão entretida da narrativa fílmica, ela se coloca num campo precioso da subversão cultural contra a ordem "imbecilizante" do capital. Neste sentido, devemos ter como meta, ir além da tela no sentido de criar, por meio da prática cineclubista, espaços de produção de conhecimento crítico.

Vivemos, de fato, uma total massificação de valores [...]. É preciso mostrarmos a alma humana destituída de fórmulas convencionalizadas, de estereótipos. É necessário que o homem redescubra o seu próprio significado diante do mundo codificado que se lhe apresenta (TREVIZAN, 1998, p. 96).

Diante da importância de promover o trabalho com o cinema em contextos de formação, Souza (2014) compartilha da experiência de dois planos de trabalho que propõem a prática cineclubista em Monteiro- $\mathrm{PB}$, cidade do cariri ocidental paraibano que, assim como $90 \%$ das cidades brasileiras, não tem sala de cinema.

No Campus VI da Universidade Estadual da ParaíbaUEPB, o Núcleo de Espanhol desenvolve semanalmente o "Cinema dos outros", que visa a exibição e discussão de filmes do universo hispânico, com vistas à alteridade e à interculturalidade. O projeto "cinema como arte, 
entretenimento, ferramenta e prática social" que lideramos tem três focos de atuação: i) complementar e fortalecer a prática cineclubista: exibição, análise e discussão no campus; ii) constituir um grupo interdisciplinar de estudos e pesquisas sobre o cinema; iii) desenvolver oficinas para produção de material didático e formação de multiplicadores na aquisição do E-LE mediada pelo cinema.

Macedo (2005, p. 20) relata que $60 \%$ dos jovens entre 15 e 29 anos nunca foram ao cinema. No caso da pesquisa de Souza (2014), uma coleta de dados feita com os alunos do curso de Letras-Espanhol do Campus VI revelou que $59 \%$ deles nunca foram ao cinema. Um total de $42 \%$ dos participantes declarou que raramente assiste a filmes, em casa ou com amigos. Esses dados revelam que o público daquele contexto não tem o costume de consumir/apreciar o cinema.

\section{Algumas pesquisas que utilizam o cinema no ensino de línguas e na formação de professores}

No que concerne às pesquisas que utilizam o cinema como mediador no ensino de línguas, tivemos contato com as investigações de Garcia de Stefani (2010) e Gómez Alibés (2008). No campo da formação inicial e continuada de professores de línguas, conhecemos os trabalhos de Mayrink (2007), Souza (2014) e Garcia de Stefani (2014).

Garcia de Stefani (2010) desenvolveu uma pesquisa de mestrado na qual argumenta que embora o cinema possa configurar-se como um recurso didático eficiente para a implementação do ensino comunicativo de línguas, por seu caráter lúdico e por sua capacidade de promover maior envolvimento dos alunos na realização de atividades 
significativas, percebe-se que seu uso ainda é bastante limitado no âmbito de ensino de língua estrangeira.

A partir desta constatação, o objetivo da pesquisa qualitativa de base etnográfica desenvolvida pela pesquisadora foi investigar o uso do filme Diários de Motocicleta como conteúdo didático no contexto de ensino de espanhol como língua estrangeira, tomando por base os pressupostos teóricos da aprendizagem significativa. A pesquisadora argumenta que a análise dos dados revela que o filme representa uma maneira eficaz de apresentar o insumo linguístico contextualizado, de envolver os alunos em atividades de interação e negociação de sentidos, de estimular o pensamento crítico e o conhecimento de mundo, além de contribuir significativamente para o desenvolvimento da autonomia do aluno como aprendente de línguas.

Gómez Alibés (2008) propõe a substituição das tradicionais gravações de áudio dos livros didáticos por fragmentos de filmes como uma nova visão da apresentação de situações cotidianas na aula de E-LE.

O autor argumenta que há uma série de situações típicas pelas quais qualquer pessoa pode passar vivendo em um país estrangeiro que a maioria dos livros didáticos de E-LE, geralmente, apresentam em suporte de áudio, dentre elas: fazer pedidos em um restaurante, perguntar o caminho para um pedestre, registrar um boletim de ocorrência em uma delegacia, realizar operações bancárias, resolver problemas no aeroporto, se expressar em um consulta médica, alugar um imóvel, interagir em uma entrevista de emprego, fazer uma reserva em um hotel. 
O pesquisador conclui ser possível substituir esses arquivos de áudio tradicionais por trechos de filmes que apresentam usos diários e reais da linguagem de forma autêntica e próxima da realidade.

Em sua pesquisa de doutorado, Mayrink (2007) lançou mão de produções cinematográficas com o objetivo descrever e interpretar o fenômeno da formação crítico-reflexiva de professores em formação inicial (alunos de Letras e Pedagogia) mediada por filmes. A partir da perspectiva sociocultural de Vigotski, a autora compreendeu que os filmes se constituem em signos mediadores com potencial para o desenvolvimento crítico-reflexivo do futuro professor.

Souza (2014), em sua tese de doutorado, argumenta que a cultura de aprender e ensinar uma língua estrangeira baseia-se em teorias implícitas que são compostas por fatores como crenças, motivações, memórias, intuições e imagens, dentre outros. Dessa forma, as concepções dos agentes envolvidos na operação global do ensino de línguas exercem profunda influência em todo o processo, já que cada indivíduo, permeado por seu contexto sócio-histórico-discursivo tem suas crenças que embasam as atitudes que norteiam seu comportamento em face do complexo processo de ensino-aprendizagem de línguas.

Diante do exposto, a investigação teve como escopo analisar as crenças de professores de espanhol-língua estrangeira (E-LE) em formação inicial, no que diz respeito ao processo de aquisição/aprendizagem da língua estrangeira e ao tratamento unidade e diversidade linguística experimentada pelo espanhol no contexto do ensino desta língua para brasileiros; todas essas reflexões mediadas pelo cinema. 
Tratou-se de uma pesquisa qualitativa de cunho etnográfico que se iniciou com a compreensão panorâmica do contexto e, a partir de um grupo focal, traçou um levantamento das crenças dos participantes antes, durante e depois das oportunidades de reflexão propiciadas ao longo do semestre 2013.2, de forma a compreender, no processo, como elas se transformavam ou não por meio das atividades de reflexão propostas.

A fundamentação teórica do trabalho esteve ancorada na perspectiva sociocultural, na formação de professores de línguas, na reflexão a respeito das crenças que permeiam o complexo processo de ensino-aprendizagem de línguas e no papel do cinema como artefato semiótico mediador. A experiência reforçou a tese de que o cinema pode contribuir significativamente na formação inicial de professores de espanhol língua-estrangeira promovendo a conscientização linguística a respeito de como se adquire/ aprende a língua, bem como possibilitando o trabalho com a variação linguística no ensino deste idioma para brasileiros a partir do cinema, considerado - conforme a perspectiva sociocultural que adotamos - como artefato cultural, ferramenta de mediação simbólica potencializadora do desenvolvimento humano.

Atualmente, Garcia de Stefani (2014) realiza sua pesquisa de doutorado tendo como temática a formação continuada de professores de inglês e espanhol em serviço com o apoio do cinema, com vistas a fomentar o desenvolvimento e a aplicação em sala de aula de atividades didáticas a partir conteúdo fílmico à luz dos letramentos críticos. 


\section{O exercício da competência intertextual}

Já é consenso entre os estudiosos que quanto mais o espectador de cinema se empenhar em compreender/ analisar os filmes aos quais assiste, maiores serão a chance de se aproximar da intencionalidade e seleção de sentidos pretendidas pelos idealizadores, das características culturais e das ideologias de suas escolhas, permitindo compará-las a sua própria cultura e valores.

Neste sentido, Trevizan (1998, p. 86) aponta que o potencial artístico de um bom filme não se sustenta somente no reconhecimento da credibilidade da história contada, mas reside, sobretudo, na possibilidade de a linguagem criada estabelecer com o espectador um nível profundo de comunicação intelectual, filosófica, psicológica, emocional, fazendo com que ele reflita sobre si mesmo e sobre o outro.

A recuperação do diálogo entre textos diversos, tomando aqui texto no sentido amplo, enriquece a competência intertextual, o que permite que o espectador recupere experiências e leituras anteriores. Mikhail Bakhtin valoriza a interação entre os textos, isto é, o dialogismo do discurso: "a presença de muitas vozes que não se fundem em uma consciência única, mas participam de um dinamismo dialógico" (DI CAMARGO, 2009, p. 32).

O cinema representa uma instância privilegiada de relações dialógicas e intertextuais, de construção ideológica e interação social, devido ao inter-relacionamento das mais variadas modalidades de signos - sistematizados, não apenas pela 
palavra, mas, igualmente, pelo som e pela imagem - na constituição de seu produto final, o texto fílmico (DI CAMARGO, 2009, p. 46).

Todo texto é sempre resultado da uma rede complexa de discursos porque todo sujeito criador está sempre em sintonia cultural com o seu tempo histórico eem sua produção recupera outras experiências de leitura (TREVIZAN, 1998). Para o professor, proporcionar ao aprendiz oportunidades para desvendar a pluralidade contida em um filme pode acrescentar muito ao desenvolvimento global enquanto indivíduo:

a importância da exploração em sala de aula, da natureza intertextual do texto fílmico. Assim, como o texto literário, também o texto fílmico é construído pelo processo dialogante com outros textos. Escritores, pintores, cineastas, artistas em geral dialogam culturalmente, resgatando, nos textos produzidos, o tesouro enciclopédico do já dito (ECO, 1991:22). É possível, portanto, em sala de aula, recuperarmos o diálogo de um filme em análise com outros filmes e também com textos estranhos ao universo cinematográfico (TREVIZAN, 1998, p. 91). 
Levar o cinema para a sala de aula pode implicar em proporcionar aos aprendentes ${ }^{4} \mathrm{um}$ trabalho interdisciplinar que pode ir desde o resgate da história da sétima arte, por exemplo, até o desenvolvimento de conceitos da linguagem cinematográfica que propiciem elementos básicos de análise que permitam ler além das imagens. Dentro da diversidade de obras disponíveis, pode-se trabalhar, com as devidas adaptações, desde dança, música, teatro, literatura, culinária e até mesmo oficinas para os alunos produzirem seus vídeos.

Neste sentido, compartilharemos aqui duas pesquisas das quais participamos e que abordam o exercício da intertextualidade. O trabalho de Souza et. all. (2007) relata uma investigação desenvolvida com alunos do $5 .^{\circ}$ ano do ensino fundamental de uma escola pública do interior paulista. Na ocasião, tivemos como objetivo principal compreender o ponto de vista dos alunos acerca da percepção da intertextualidade entre os clássicos da literatura infantil (Branca de Neve e os setes anões, Cinderela e a Bela Adormecida) e o filme Shrek (2001).

A experiência envolveu a leitura e dramatização dos clássicos, seguida pela comparação dos contos infantis e da análise dos elementos que constituem o gênero. Na sequência, houve a projeção do filme e o levantamento das relações entre o filme e as histórias. Na ocasião, verificou-se a recuperação do diálogo entre o filme com os contos trabalhados, bem como a relação entre as questões tratadas e a realidade dos alunos envolvidos.

4 Termo utilizado por Shulman (1986) apud Brzezinski (2002, p.2) para designar aquele ser que aprende como autor de sua própria aprendizagem. 
O artigo de Souza \& Bongestab (2012) mostra que, ao tomar o cinema como arte e entretenimento, também existe a possibilidade de significá $\square$ lo como ferramenta e prática social propícios para o exercício da intertextualidade. Nele, exploramos a presença das "muitas vozes" que compõem a produção cinematográfica de Carlos Saura, um diretor de cinema e escritor multifacetado, que entrelaça literatura, pintura, dança, música, fotografia, teatro, em suas obras.

\section{Considerações}

Os possíveis diálogos entre a arte cinematográfica e a educação foi o fio condutor no trajeto que traçamos neste texto. Destacamos a capacidade da sétima arte para representar a vida em seus múltiplos aspectos, enfatizando o potencial representacional das inquietações e desejos mais íntimos da alma humana. Tecemos considerações acerca das várias vias de estudo com vistas à compreensão do cinema, com foco na indústria, nas artes, nas invenções, no entretenimento e ressaltamos seu potencial na formação de novas gerações.

A partir de visões múltiplas e ao mesmo tempo complementares, isto é, tomando o texto fílmico como arte, entretenimento, ferramenta e prática social traçamos reflexões acerca da sociedade contemporânea submersa em imagens, sons e movimentos, discorremos sobre os vários usos do cinema e vídeo na escola, apresentamos a pesquisa em educação com base nas artes, bem como as contribuições da prática cineclubista para a formação humana e a importância da sétima arte no exercício da competência intertextual. 
Ao longo de cada item relatamos pesquisas e trabalhos que expandem as questões aqui apresentadas de forma a ilustrar a riqueza da sétima arte, que em sua composição incorpora várias das outras manifestações artísticas experimentadas pelo ser humano e nos coloca diante do desafio de promover via ensino, pesquisa e extensão a arte de ver objetivando leituras plurais do mundo.

\section{Referências}

ADAMSON, A. \& JENSON, V. (Dir.) Shrek. DVD: EUA, 2001.

ALMEIDA, M.J. A linguagem na nova oralidade: imagens e sons In: Coletânea Lições com cinema. São Paulo: FDE, 1994, p. 117-124.

ALVES, G. "O cinema como experiência crítica: tarefa política do novo cineclubismo no século XXI". In: ALVES, G.; MACEDO, F. Cineclube, cinema $\mathcal{E}$ educação. (Orgs.) Londrina: Praxis, Bauru: Canal 6, 2010.

ANDRADE, J.B. Cineclube, Cinema e Educação. In: ALVES, G.; MACEDO, F. (Orgs). Cineclube, cinema \& educação. Londrina/Bauru: Praxis/Canal 6, 2010.

BRZEZINSKI, I (Org.). Profissão professor: identidade e profissionalização docente. Brasília: Plano Editora, 2002.

DENZIN, N. K. The many faces of emotionality. In: ELLIS, C.; FLAHERTY, M. G. (Eds.). Investigating subjectivity. Newbury Park, CA: Sage Publications, 1992. 
DI CAMARGO, I.J. A Memória de Futuro analisada pela Linguagem Cinematográfica: Diálogos entre a Teoria do Cinema e Mikhail Bakhtin. Dissertação (Mestrado em Linguística). São Carlos: UFSCar, 2009.

DIAMOND, C. T. P.; MULLEN, C. A. The postmodern educator: arts-based inquiries and teacher development. New York: Peter Lang, 1999.

EISNER, E. W. The enlightened eye. New York: Macmillan Publishing Company, 1991.

EISNER, E. W. "The promise and perils of alternative forms of data representation". Educational Researcher, v. 26, n. 6, p. 4-10, 1997.

FABRIS, E.T.H. Em cartaz: o cinema brasileiro produzindo sentidos sobre escola e trabalho docente. Tese (doutorado em educação). Porto Alegre: UFRGS, 2005.

GRAY, R. E. Performing on and off the stage: the place(s) of performance in arts-based approaches to qualitative inquiry. Qualitative Inquiry, v. 9, n. 2, p. 254-267, 2003.

MAYRINK, M.F. Luzes... câmera... reflexão: formação inicial de professores mediada por filmes. Tese (doutorado em Linguística Aplicada e Estudos da Linguagem). São Paulo: PUC, 2007.

MACEDO, F. Cineclube e autoformação do Público. In: ALVES, G.; MACEDO, F. (Orgs). Cineclube, cinema \& educação. Londrina/Bauru: Praxis/Canal 6, 2010. 
MORAN, J.M. O vídeo na sala de aula. Comunicação $\mathcal{E}$ Educação. São Paulo: ECA/Ed. Moderna. Jan./abr. 1995, n. 2, pp. 27-35.

MORAN, J.M. Os vários usos do cinema e de vídeo na escola In: NAPOLITANO, M. Como usar o cinema na sala de aula. São Paulo: Contexto, 2003.

MORAES, A. C. A escola vista pelo cinema: uma proposta de pesquisa. In: Maria da Graça Jacintho Setton. (Org.). A cultura da mídia na escola: ensaios sobre cinema e educação. 1 ed. São Paulo: Annablume/USP, 2004, v. 1, p. 53-66.

NAPOLITANO, M. Como usar o cinema na sala de aula. São Paulo: Contexto, 2003.

PINHEIRO, S.R.L. Educação, memória e cinema: um estudo comparativo das representações sociais da escola em "Os incompreendidos" e em "Machuca". Dissertação (mestrado em educação). São Paulo: USP, 2010.

SOUZA, F.M.; BONGESTAB, C. Texto fílmico: imagem e intertextualidade. In: SOUZA, F.M.; GHAZIRI, S.M. (Orgs.). Pesquisa e ensino de leitura no mundo atual: debates múltiplos. São Carlos: Pedro \& João Editores, 2012, v. 1, p. 18-37.

SOUZA, F.M.; CRUZ, M.L.O.B.; GAMA, A.P.F. “O cinema no aperfeiçoamento das competências do aprendiz de línguas (materna e estrangeira)". In: PINHO, S.Z.; SAGLIETTI; J.R.C. (orgs.) Núcleos de Ensino - Projetos de 2005. São Paulo: Cultura Acadêmica/UNESP Publicações, 2007. pp. 487-499. 
TELLES, J.A. Pesquisa educacional com base nas artes: pensando a educação dos professores como experiência estética. In: Educação e Pesquisa (USP), vol.32, n. ${ }^{\circ}$ 3, 2006, pp.509-530.

TELLES, J.A. Modos de representação: o espetáculo teatral como dispositivo de reflexão e representação do desenvolvimento do professor. In: VIEIRA-ABRAHÃO, M.H. (Org.) Prática de ensino de língua estrangeira: experiências e reflexões. Campinas: Pontes Editores, ArteLíngua, 2004.

TREVIZAN, Z. As malhas do texto: escola, literatura, cinema. São Paulo: Clíper, 1998.

TURNER, G. Cinema como prática social. São Paulo: Summus, 1997

VERTOV, D. O Homem da Câmera (Chelovek s Kinoapparatom) (1929). Disponível em: Utorrent Download. 